\begin{tabular}{|c|c|c|}
\hline & $\begin{array}{l}\text { ANNALES INSTITUTI SLAVICI } \\
\text { UNIVERSITATIS DEBRECENIENSIS }\end{array}$ & \\
\hline SLAVICA XLVIII & 2019 & DEBRECEN \\
\hline
\end{tabular}

Александр УШКАРЕВ

\title{
ПУБЛИКА ИСКУССТВА: МИФЫ И РЕАЛЬНОСТЬ
}

The Audience of Art: Myth and Reality

\begin{abstract}
Interest in the audience arose while art became public and since then it has not weaken, rather it has become more and more special. For more than a century the audience of art has been the subject of systematic scientific research. Why then is the problem of the relationship between art and its audience becoming once again a topical issue? The consequences of the civilizational shifts in the last decade have clearly shown: the things that have for a long time been considered true suddenly turn out to be illusive or banal in the changing world. In the modern market paradigm of the artistic culture development, the problem of the relationship between art and its audience acquires a new sound. A theater, a museum or a concert organization needs not the social and cultural portrait of the spectator, but an understanding of the causes and characteristics of its consumer behavior in the wider context of cultural life. And the first step to overcome the communication barriers between art and its potential consumers should be the abandonment of stereotypes and outdated research approaches.
\end{abstract}

Keywords: audience of art, sociological researches of the audience, cultural consumption, motivation, cultural activity, cultural capital

«...Публика, невежественная, дикая. Даю ей самую лучшую оперетку, феерию, великолепных куплетистов, но разве ей это нужно? Разве она в этом понимает что-нибудь?

Ей нужен балаган! Ей подавай пошлость!»

А. П. Чехов. Душечка

Эта сакраментальная фраза чеховского персонажа, антрепренера Кукина пример расхожих стереотипов о театральной публике, которые складывались едва ли не столетиями и даже нередко соответствуют действительности. Многолетний опыт настолько расширил наши представления о публике, что иной раз кажется, что мы знаем о ней все, ну или почти все. Это вам скажет и любой из нынешних театральных администраторов: опыт вообще великий учитель. Уже давно всем известно, например, что в публике искусства больше женщин, чем мужчин, что, с одной стороны, публика жаждет развлечения, но с другой, - она более образованна и культурна, а общение с искусством развивает людей 
духовно и делает их лучше...Однако, рисуя образ типичного зрителя, множество «наблюдений из жизни» по сути выстраивали систему стереотипов, не облегчая, а лишь затрудняя его содержательное понимание. Конечно, нелепо приписывать всем или даже большинству представителей публики одни и те же черты. Точно так же нелепо думать, что отношение к искусству определяется гендерными различиями или образованием, а люди одного возраста имеют сходные художественные потребности. Реальность оказывается куда сложнее и многообразнее!

Представляя в этой статье некоторые результаты исследования современной публики искусства, мы не ставили задачу подтвердить или опровергнуть стереотипы, по которым принято судить о зрителе. Задача в том, чтобы наполнить их реальным смыслом, оживить идеальный статистический образ зрителя и увидеть его в действии. Материалом для этой работы послужили, главным образом, не опубликованные источники, а эмпирические факты - доказательства, добытые в десятках и сотнях социологических опросов, проведенных по городам и весям театральной России, уникальные массивы данных первичной социологической информации. Социологические опросы театральных зрителей проводились сотрудниками Отдела общей теории искусства и культурной политики Государственного института искусствознания (ГИИ), Москва, начиная с 1992 года. За четверть века сотрудниками Отдела было опрошено более 52 тыс. зрителей более чем в 50 театрах Москвы, Санкт-Петербурга, Краснодара, Красноярска, Магнитогорска, Якутска, Челябинска, Перми, Ярославля, Петрозаводска, Новгорода. Материалы этих опросов в последние годы были дополнены исследованиями концертной публики и посетителей Государственной Третьяковской галереи. Столь представительный массив исходных данных обеспечивает высокую достоверность полученных результатов и позволяет вписать их в широкий контекст культурной жизни.

\section{Методология}

Значение аудитории состоит в том, что она - не только воспринимающая сторона и объект воздействия. Это активный участник художественного процесса, способный оказывать существенное влияние на развитие искусства. Изучение аудитории с реальной опорой на эмпирические факты представляется необходимым условием успешного функционирования любой организации культуры и искусства, а также способом изучения художественной жизни общества, состояния и проблем современной культуры.

Многочисленные исследования аудитории искусства, проводившиеся по всему миру в прежние годы, позволили воссоздать социальный портрет публики, определить ее основные культурные и психологические особенности, т.е. многое из того, что отличает аудиторию искусства от населения в целом. Однако наиболее ценные из достигнутых результатов состоят в понимании, что отношения человека с искусством не случайны, они детерминированы как объективными характеристиками и интеллектуально-культурными ресурсами личности, так и влиянием социально-культурной среды. Наряду с этим 
укрепилось осознание того, что закономерности, обнаруженные на материале одного вида искусства, как правило, проявляются и в других его видах, хотя и с некоторой спецификой.

Традиционные попытки социологии искусства объяснять поведение людей исключительно их социально-демографическими и другими объективными характеристиками сегодня представляются бесперспективными. Они не дают существенного приращения знания, а в некоторых случаях приводят исследователей к сомнительным выводам. Приведем относительно свежий пример. Систематизируя эмпирические материалы социологических исследований аудитории посетителей Государственного Русского музея (Санкт-Петербург), его авторы пишут: «данные социологических исследований позволяют утверждать, что существует сходство структуры аудиторий крупных художественных музеев Санкт-Петербурга и Москвы, то есть одна и та же публика, сходная по своим социально-демографическим и социокультурным характеристикам, посещает такие учреждения, как музеи изобразительного искусства» [ИЕВЛЕВА-ПОТАПОВА 2013: 31]. Дальше - вывод: «Следовательно, меняются интересы зрителей к различным стилям и направлениям в искусстве согласно разным возрастным периодам их жизни» [ИЕВЛЕВА-ПОТАПОВА 2013: 93]. Очевидно, что механистическая трактовка социологических фактов не только бессмысленна, но и вредна. Такой, доведенный до абсурда традиционный подход настойчиво формирует убеждение, что люди, имеющие одинаковые социально-демографические признаки, и ведут себя одинаково, и являются по сути «одной и той же» безликой массой.

Относительно медленное продвижение в понимании организациями искусства своей аудитории и сохраняющиеся проблемы стимулировали поиски новых принципов концептуализации публики и объяснения закономерностей потребительского поведения. Так, на волне активных поисков свежих идей Институт Гэллапа в 1996 г. представил новую ценностно-ориентированную систему социально-психологический сегментации - так называемый «Компас Гэллапа» (Gallup Kompas) ${ }^{1}$, который должен был, по замыслу создателей, обеспечивать разностороннее понимание потребительских настроений, ценностей и образа жизни людей. Этот сложный психографический инструмент основан на факторном анализе ответов респондентов на специальные тестовые вопросы и позволяет позиционировать респондента на виртуальной двухмерной системе координат между полюсами «социально- или индивидуально-ориентированный» и «современный или традиционный», включая промежуточные сектора. Впрочем, и такой подход ненамного приблизил научное сообщество к пониманию истоков потребительского поведения в искусстве. Введя в интегральный образ потребителя социально-психологические характеристики, он лишь добавил к списку устойчивых структурных диспропорций, отличающих аудиторию искусства от населения, еще одну.

1 Gallup Kompas. Retrieved 02.02.2019 from http://www.gallup.dk/. 
Таким образом, ни методы традиционной социологии искусства с ее повышенным интересом к социально-демографическим характеристикам респондентов, ни социально-психологические измерения в чистом виде не дают понимания тенденций социального поведения и могут привести к пренебрежению некоторыми потенциально важными его детерминантами. Критический анализ современного научного знания убеждает, что, несмотря на достигнутые результаты, сотни и тысячи исследований, проведенных по всему миру и направленных на изучение того, кто и как потребляет искусство, мало продвинули нас в понимании субъективных причин и поведенческих закономерностей отношения человека к искусству.

Для воссоздания реальной картины культурной активности и устойчивых особенностей потребительского поведения различных групп театральных зрителей исследователям ГИИ потребовалось если не переосмыслить само понятие зрителя, то, по крайней мере, по-новому взглянуть на характер его взаимодействия с искусством. На этой основе были сформулированы новые подходы к концептуализации театральной публики и сегментации театрального рынка, адекватные современным задачам.

Суть предложенного подхода состоит в следующем. Зрители - это, прежде всего, отдельные люди с присущими им личными вкусами и предпочтениями. Среди них есть такие индивидуумы, потребности которых в искусстве могут быть в равной степени удовлетворены в результате посещения театра, филармонического концерта, эстрадного или циркового представления и т.д. Для этой части потенциальных зрителей все представленные на афише художественные продукты, создаваемые различными учреждениями искусства, творческими индивидуальностями или коллективами, являются множеством взаимозаменяемых культурных товаров-субститутов. Поэтому за досуг и деньги таких потребителей конкурируют все организации исполнительских искусств, причем конкурируют при полном отсутствии чьей-либо монополии [РУБИНШТЕЙН и др. 1998: 226-248].

Другой группе зрителей присущи более развитая структура потребностей и дифференцированное отношение к искусству. Для них посещение, скажем, драматического театра уже не может компенсировать потребность в музыкальных спектаклях, так же, как, например, опера не может заменить балет и т.п. Таким образом, по мере дифференциации зрительских потребностей происходит индивидуализация и самого художественного продукта. Он приобретает в глазах части публики все больше особых и даже уникальных свойств. Дальнейшее расширение и детализация требований к художественному продукту со стороны потенциального потребителя резко сужает выбор, уменьшает число его «продавцов», снижает возможности конкуренции и тем самым укрепляет монопольные тенденции. В предельном случае мы имеем дело с абсолютной монополией создателей и исполнителей уникального сценического произведения для потенциальных потребителей с абсолютно избирательным вкусом.

В качестве основания для выделения соответствующих зрительских групп выступают следующие критерии: ориентация на определенный тип театра 
(драма, опера, балет и т.д.); предпочтение определенных творческих коллективов; а затем - и более тонкие признаки: факторы драматургических привязанностей и наличие персонифицированного интереса к конкретным создателям спектакля. Типологический признак таким образом был перенесен из области объективных характеристик респондента в субъективную область его восприятия искусства и потребительского поведения. Это концептуальное отличие нового подхода позволило продвинуться от традиционной констатации социально-демографических фактов в направлении понимания закономерностей культурной активности зрителей. Такой подход позволил существенно повысить практическую значимость эмпирических исследований театральной публики, особенно исследований маркетинговой направленности.

Между тем абсолютно универсальных исследовательских подходов не существует, а их выбор определяется целями и задачами конкретного исследования. Так, в ходе изучения аудитории посетителей Государственной Третьяковской галереи наряду с решением комплекса стандартных задач, мы предприняли попытку определения драйверов культурной активности - тех причин и факторов, которые побуждают людей к потреблению искусства, получению информации об искусстве, а также к собственной творческой деятельности. В связи с этим был применен новый теоретический подход, опирающийся на идею П. Бурдье о культурном капитале как накапливаемом интеллектуальнокультурном ресурсе личности [БУРДЬЕ 2002: 60-74]. Это потребовало провести операционализацию понятия культурного капитала и разработать методику определения его количественной меры, которая наряду с мотивациями и индивидуальными предпочтениями стала одним из содержательных типологических признаков аудитории. Результаты исследования убедительно показали потенциал и высокую объясняющую способность культурного капитала как одного из ключевых драйверов потребления искусства [УШКАРЕВ 2018б: 178-187].

Далее мы приводим некоторые результаты эмпирических исследований, уточняющие сложившиеся представления об аудитории искусства.

\section{Мифы и реальность}

Публика искусства сохраняет относительную стабильность во времени, и наше исследование подтвердило справедливость многих хорошо известных фактов. В основном это касается самого поверхностного ее описания по социально-демографическим признакам. Так, по данным проведенных нами опросов, в составе аудитории разных видов искусства, в том числе театра, зафиксированы сходные гендерные, возрастные, социальные и некоторые поведенческие закономерности: преобладание в аудитории женщин, людей с высшим образованием, представителей гуманитарных профессий и т.д. Однако исследования театральной публики, проведенные с использованием описанного выше подхода, ясно показали, что каждой из гомогенных групп зрителей присущи свои, особенные художественные предпочтения и черты поведения на театральном рынке [РУБИНШТЕЙН 1998; УШКАРЕВ 2011]. Наши исследования 
с очевидностью показали: «среднего» зрителя не существует, а многие «известные истины» стали расхожими стереотипами, которые давно не соответствуют действительности и немногим отличаются от тех, что высказывал чеховский персонаж!

Так, в ряду устойчивых стереотипов бытует мнение о театралах как об исключительно культурных, образованных и гармонично развитых личностях. Во многих случаях это действительно так. Однако анализ структуры зрительской аудитории по личностным потенциалам [ФОХТ-БАБУШКИН 1987, ФОХТ-БАБУШКИН и др. 1982] и избирательности театральных потребностей показал, что разносторонне развитые личности с высокой избирательной способностью, в совокупной театральной аудитории все же составляют меньшинство. Они представлены во всех зрительских группах, но их доля повышается по мере расширения и углубления художественных потребностей. Это понятно: культурный потенциал личности, определяя потребность человека во взаимодействии с миром духовных ценностей, одновременно дает ему и способность к пониманию искусства. Вместе с тем расчеты на примерах аудитории театральных спектаклей разных видов показали, что максимальная избирательность в отношении театрального искусства одновременно означает превалирование специфического театрального вкуса над интегральным, т.е. некоторую односторонность в развитии личности. Мнение о завзятых театралах как разносторонне и гармонично развитых людях - миф!

В целом мы подтвердили тот известный факт, что любое серьезное искусство в гораздо большей степени привлекает людей образованных: действительно, образованным в искусстве открывается то, чего не видят необразованные. Почему? Эмпирически установленные факты убедительно подтверждают теоретические установки: возможность непосредственного и свободного восприятия в искусстве - иллюзия. Восприятие всегда происходит с определенных позиций, и произведение искусства имеет смысл только для того, кто обладает культурной компетентностью, то есть знает код, которым закодировано художественное сообщение [BOURDIEU 1994: 404-429]. Искусство восприятия как форма «культурной дешифровки» не является априорной способностью человека, оно приобретется в результате передачи культурных кодов через семейное воспитание и образование в широком смысле этого слова. И даже если образование не имеет непосредственного отношения к искусству, оно развивает обобщенные способности и навыки, создает чувство принадлежности к «культивированному» классу и владения культурными кодами, порождая тенденцию приобретать эквивалентные категории и в других областях.

Эмпирически подтверждая эти теоретические положения, мы особо подчеркиваем неоднозначность роли образования в культурной активности человека. С одной стороны, уровень образования отражает меру приобретенных познавательных способностей, необходимых для культурного потребления [STIGLER-BECKER 1977: 76-90]. С другой стороны, образование, как важная составляющая социального статуса человека, создает и некий статусный эффект, 
благодаря которому посещение культурных мероприятий иногда обуславливается не столько культурными потребностями, связанными с присвоением символического содержания произведений искусства, сколько является средством, используемым образованным классом для выделения и закрепления своего привилегированного социального положения [BOURDIEU 1977: 171183]. Формальный показатель уровня образования, таким образом, - совсем не то же самое, что измерение его последствий с точки зрения когнитивных навыков и знакомства с миром идей.

В плане культурного потребления важна именно способность воспринимать символическое содержание искусства, которая приносит огромную пользу и удовольствие тем, кто ею наделен. Нам удалось зафиксировать тот факт, что приобретаемая в процессе раннего семейного воспитания и образования, эта накапливаемая и развиваемая в процессе культурного потребления способность, которую П. Бурдье называл «культурным капиталом в инкорпорированном состоянии» [БУРДЬЕ 2002: 64], является основным драйвером потребления искусства, именно она определяет степень содержательности потребительской мотивации и частоту контактов человека с искусством. Эта способность лежит в основе так часто отмечаемой внешней связи образования с эстетическими потребностями, предпочтениями и культурной активностью. При этом анализ убедительно показал нетождественность показателей образования и культурного капитала личности [УШКАРЕВ 2018б: 178-187].

Способность понимать и воспринимать символическое содержание искусства - не врожденный, а накапливаемый и развиваемый ресурс личности. Этим объясняется эмпирически доказанный факт, что он в значительной мере связан не только с уровнем образования, но и с возрастом, и с наличием культурных традиций в семье, и с возрастом приобщения человека к искусству. То, что возраст отражает отдельные измерения культурного капитала, отмечается и некоторыми западными исследователями [SEAMAN 2006: 415-472]. Проблема в том, что именно эти легко фиксируемые факты статистической связи пола, возраста, образования и некоторых других измеримых характеристик личности с особенностями потребительского поведения порождают иллюзию того, что такие сложные явления как отношение человека к искусству или художественный вкус могут быть объяснены такими простыми причинами как возраст или уровень образования. Наше исследование показало, что это заблуждение: дело не в возрасте как таковом, а в тех накапливаемых характеристиках личности, которые определяют отношение к искусству и связаны не только с возрастом [УШКАРЕВ 2017a: 36-49].

Еще один миф состоит в том, что люди ходят в театр, музей или на концерт исключительно ради искусства. Это, конечно, не так. Кроме содержательных мотиваций, связанных с восприятием художественных произведений, контакты человека с искусством могут быть обусловлены и целым рядом других мотивов, непосредственно с искусством не связанных. При этом тип мотивации существенно влияет на частоту контактов человека с искусством. Так, значимым положительным фактором культурной активности является наличие 
содержательных мотивов. К ним относятся не только художественные, но и социально-культурные, просветительские и коммуникативные аспекты. Анализ показал, что при прочих равных условиях те, чья мотивация состоит в желании посетить конкретный спектакль или выставку, получить специфические впечатления от общения с искусством или приобщить к искусству ребенка, как правило, посещают театры и музеи чаще.

Расчеты показали наличие положительной статистически значимой корреляции содержательных мотиваций для контактов с искусством и предложенных нами измерений культурного капитала [УШКАРЕВ 2018а: 69-78]. Закономерность такова: чем выше мера культурного капитала личности, тем более интеллектуально-содержательными оказываются ее художественные потребности и мотивы приобщения к искусству и тем большей интенсивностью характеризуются контакты человека с искусством. Между тем рекреационные мотивы (отдохнуть, провести свободное время или отсутствие артикулированных причин посещения) являются фактором, существенно снижающим интенсивность контактов человека с искусством. Установленная закономерность не случайный результат, она косвенно подтверждается также и некоторыми европейскими исследованиями [BRIDA et al. 2014].

В театрально-концертной или музейной жизни бывают мероприятия особого рода, которые мы условно определяем как «значимые культурные события». Проведенные нами социологические опросы показали: подобный подчеркнуто декларируемый статус мероприятия, вне зависимости от его жанровой или видовой принадлежности, часто способствует проявлению повышенного интереса к нему со стороны определенной части образованной публики, бомонда, склонного к престижному потреблению искусства. Этот эмпирически установленный факт позволяет говорить о большой значимости престижно-статусных мотивов в культурном потреблении, а также косвенно подтверждает предположение о наличии статусного эффекта образования. Вне зависимости от вида искусства, именно статусные мотивы зачастую становятся главными детерминантами культурной активности образованной культурнопрестижной публики, которую в большом количестве фиксировали наши опросы на разного рода значимых культурных мероприятиях в театрах, на концертах и художественных выставках. Этот особый тип мотивации представляет, на наш взгляд, не только культурологический, но и очень показательный маркетинговый феномен.

Большая роль престижно-статусных мотиваций показательна с точки зрения соотношения общего и особенного в разных видах искусства. И престижно мотивированный театральный бомонд, и аудитория значимых музейных событий или статусных выставок по своим мотивационным и поведенческим характеристикам оказались очень схожи: эта общекультурная публика имеет широкий спектр интересов и стремится по возможности посещать значимые культурные мероприятия любых видов. В ней оказывается достаточно много пре- 
стижно-мотивированных, но не обладающих артикулированными художественными потребностями посетителей, которые могут быть причислены к символическим потребителям искусства.

Публикой совершенно другого рода является аудитория, специфически ориентированная на определенный вид искусства. В исполнительских искусствах это театралы и меломаны, в музее - посетители постоянных экспозиций; те и другие мотивированы преимущественно содержательным интересом. В такой публике, в отличие от престижно-статусной, оказывается относительно больше не только случайных неофитов, учащейся молодежи и любителей, но и профессионалов; эта публика - одновременно и приобщающаяся, и специальная.

Диалектика общего и особенного проявляется также в роли тех или иных факторов культурного потребления. Роль мотивации и культурного капитала, одним из источников которого является образование, в культурной активности бесспорна, но разные виды искусства предъявляют различные требования к своим потенциальным потребителям. Наименее требовательными к культурным компетенциям своих зрителей из всех проведенных нами эмпирических опытов оказались мюзикл и основная экспозиция Третьяковской галереи [УШКАРЕВ 2019]. МЫ объясняем это тем, что мюзиклы относятся к тому роду сценических представлений, отличительные особенности которых составляют зрелищность, легко запоминающаяся музыка и увлекательный сюжет. Способность к восприятию этих качеств тоже, конечно, не может быть врожденной [BOURDIEU 1994: 404-429], но воспитывается она не только в результате целенаправленных усилий и опыта общения с искусством, но и широким контекстом бытовой и массовой культуры как неотъемлемой части повседневной жизни. Она характеризует начальный, низший уровень художественной компетентности зрителя.

Этот вывод подтверждается и тем, что, исходя из набора досуговых предпочтений и в соответствии с предложенной нами типологией досугового поведения [УШКАРЕВ 2017б: 148-156], мы можем характеризовать основную массу зрителей мюзикла «Граф Орлов» как людей, предпочитающих не столько культурный, сколько сочетание развлекательного и активно-деятельного типа досуга. Такое сочетание досуговых стратегий предполагает, что большую часть свободного времени люди тратят на развлечения и отдых, хотя отнюдь не только бездеятельный.

Постоянная экспозиция Основного здания Третьяковки, представляющая классику русского изобразительного искусства, также во многом ориентирована на широкую аудиторию, работу с учащейся молодежью и просветительство. Более высокие требования к художественной компетентности своих потребителей предъявляют концерты классической музыки, серьезные музыкальные или драматические «авторские» спектакли, восприятие которых оказывается наиболее сложным и требующим соответствующей подготовленности. С другой стороны, мы отмечаем факт, что требования к подготовленности публики зависят не только от вида искусства или жанра представления. Не меньшее значение имеют индивидуальные особенности произведений искусства. 
Оценивая структуру художественных предпочтений и тенденции зрительского спроса, мы отмечаем, что современная публика драматического театра в своем репертуарном выборе ориентируется прежде всего на участие в спектакле популярных актеров. В последние годы эта тенденция только усиливается, отражая преобладающий взгляд на актера как ключевую фигуру театрального процесса. Вместе с тем в зависимости от особенностей конкретных спектаклей и степени художественной подготовленности зрителей могут актуализироваться и другие факторы зрительского выбора: ориентация на зрелищность, интерес к классической драматургии или популярному режиссеру, экспериментальность постановки.

Как свидетельство многообразия систем культурных потребностей в искусстве мы отмечаем особенности художественных предпочтений аудитории мюзикла. Любовь к жанру мюзикла, как оказалось, не является проявлением любви к музыкальным жанрам театрального искусства или следствием, так сказать, музыкальной ориентированности зрителей. Исследование показало, как ни парадоксально это звучит, что на мюзикл ходят не ради музыки и даже не ради популярных исполнителей. Главным мотивом для посещения мюзикла «Граф Орлов» стал сюжет, история, рассказанная в спектакле, вторым - зрелищность. Не ориентированный на театр зритель, в соответствии с обыкновением, привитым современным кинематографом, шоу-бизнесом и СМИ, при посещении театрального представления рассчитывает на интригу, зрелищность, наличие эффектных декораций, костюмов и музыки, как непременный атрибут развлекательно-зрелищного досуга [УШКАРЕВ 2019: 298].

Подобный рейтинг репертуарных предпочтений воспроизводит иерархию ценностей, свойственную, главным образом, новой, художественно неподготовленной публике. Основная особенность публики мюзикла состоит в том, что эти зрители - в массе своей новые и редкие, в принципе мало интересующиеся театром. Публика, которую лишь условно можно назвать театральной, не испытывает особых привязанностей к театру и не слишком разбирается в нем; она руководствуется главным образом рекреационными мотивами, несамостоятельна в своем культурном выборе и потому часто полагается на советы друзей и знакомых. Театральные посещения для нее зачастую носят случайный характер.

Между тем театральным практикам известно, что наличие массового сегмента «зрителя-простака» для театра жизненно необходимо: ведь именно желание отдохнуть, советы друзей, случайные обстоятельства приводят в театр нового зрителя. Малоискушенный посетитель приходит не только в Московскую Оперетту, но и в Большой театр [УШКАРЕВ 2019: 214-251]. Эмпирика показывает: неподготовленные в культурном отношении посетители публично декларируют интерес главным образом к популярным образцам искусства, к тому, о чем все мы имеем хотя бы минимальное представление еще со школьной скамьи. Если наиболее подготовленная часть зрительской аудитории ГАБТа максимально представлена на авангардных оперных и балетных спектаклях, то наименее искушенная, или «начинающая», публика заполняет зрительный зал 
в основном на традиционных классических оперных постановках, олицетворяющих в массовом сознании представления о вершинах русского театрального искусства и бренде Большого. Ее привлекает в первую очередь зрелищность, меньше - участие популярных актеров, и совсем не интересует эксперимент.

Такая публика приходит и в Третьяковку, чтобы посмотреть на картины художников «Родной речи». Лишенные специфических категорий восприятия, неподготовленные посетители не могут применять к произведениям искусства никакой другой код кроме того, который дает им опыт восприятия объектов повседневного окружения. Подготовленные театралы меньшие ожидают от театра внешних атрибутов зрелища, но большие - содержательности: интеллекта, эксперимента, проявляют больший интерес к творчеству авторов или постановщиков. А для наиболее искушенных зрителей безусловной мотивационной доминантой становится потребность в специфических театральных впечатлениях. Общая закономерность в эволюции зрителя состоит в том, что по мере накопления культурного капитала и роста художественной компетентности происходит изменение художественных потребностей, и акцент с внешней, рекреативно-развлекательной стороны произведения искусства переносится на его содержательные, сущностные характеристики.

Логика культурной эволюции зрителя непосредственно связана с проблемой воспроизводства театральной аудитории, которая сегодня обнаруживает некоторые принципиальные особенности. Так, изучая аудиторию Большого театра, мы сделали вывод, что она состоит - и пополняется - в основном за счет культурно подготовленной публики, уже обладающей достаточно высоким уровнем театральной культуры и опытом общения с искусством. Совершенно иная ситуация характерна для мюзикла: его зрители являются новыми не только для конкретного сценического проекта, но и для театра вообще. Можно сказать, что мюзикл черпает свой «зрительский резерв» в основном не из совокупной московской театральной публики, а из слоев, пока не приобщенных или слабо приобщенных к театру. Иначе говоря, мюзикл, как искусство популярное, способен привлечь тех, кто в театр обычно не ходит или ходит очень редко. Давая людям, часто далеким от искусства, не только развлечение и зрелище как разновидность легкого досуга, но и более интеллектуальное содержание, мюзикл вовлекает их в театральную жизнь. Есть все основания полагать, что в этом отражается устойчивая закономерность приобщения человека к искусству: от простого - к сложному, от внешней аттрактивности к содержательности, от массового - к элитарному.

Различные группы потребителей по-разному ведут себя на театральном рынке и неодинаково восприимчивы к тем или иным маркетинговым действиям. Так, мы отмечаем неодинаковую для разных категорий зрителей значимость источников информации и каналов приобретения билетов. Исследования показали, что при всем многообразии информационных каналов, для потенциального зрителя в принципе возможно существование лишь двух основных типов информации. Первый, мотивирующий, транслирует экспертную оценку события, побуждая потенциального зрителя к посещению. Второй, 
конкретизирующий, уточняет информацию: где, когда, в какое время состоится событие, и кто из артистов принимает в нем участие. Этот тип информации лишь в редких случаях может служить самостоятельным основанием для решения о посещении культурного мероприятия. Уточняя поведенческие характеристики театральной публики, мы установили важную особенность. Поведение потенциального потребителя в информационном поле искусства имеет хотя и слабую, но статистически значимую связь с мерой культурного капитала личности: чем она выше, тем большую независимость проявляет зритель в своем культурном выборе. Он меньше ориентируется на слухи, референтные группы и чужие мнения, но больше - на объективные источники первичной информации.

В контексте главной проблемы - преодоления коммуникационных барьеров и роста посещаемости - важный результат связан с выявлением факторов, которые могут стать стимулами для повышения частоты контактов человека с искусством. Одним из существенных результатов в изучении этой проблемы стало доказательство чрезвычайно высокого значения мотивации в процессах культурного потребления. В методологическом отношении можно констатировать, что ответ на вопрос о мотивах контактов человека с искусством может выявить тип отношения к культуре с учетом главного различия между теми, кто в основном мотивирован интеллектуально-содержательными интересами, соответствующими типу зрителя, традиционно описываемого искусствоведами, культурологами и социологами, и теми, кто рассматривает посещение театра лишь как досугово-развлекательную деятельность. Впрочем, и эта последняя мотивация является хорошим стартовым предиктором участия в культурной жизни.

\section{Литература}

БурдЬЕ 2002: Бурдье, П. Формы капитала // Экономическая социология. Том 3, № 5, ноябрь.

ИЕвлЕВА-ПотАПОвА 2013: Иевлева, Н.В., Потапова, М.В. Музей и публика. СанктПетербург: РГПУ им. А.И. Герцена.

РуБинштЕйн 1998: Художественная жизнь современного общества. В 4-х тт. Т. 3. Искусство в контексте социальной экономии. Отв. ред. А.Я. Рубинштейн. Санкт-Петербург.

РуБинштейн и др. 1998: Рубинштейн, А., Скоморохова, Н., Гедовиус, Г. Сегментация театрального рынка // Отв. ред. Рубинштейн А. Художественная жизнь современного общества. В 4-х тт. Т. 3. Искусство в контексте социальной экономии. Санкт-Петербург.

УШКАРЕВ 2011: Ушкарев, А. Московский Художественный театр. После столетия. Репертуар и публика. Сб. ст. и мат-лов / Отв. ред. А. Ушкарев. Москва: ГИИ.

УШКАРЕВ 2017а: Ушкарев, А. Аудитория художественных музеев: история и методология изучения в России // Культура и искусство, № 7.

УШКАРЕВ 2017б: Ушкарев, А. Типология досугового поведения // Обсерватория культуры. Т. 14. № 2. 
УШКАРЕВ 2018а: Ушкарев, А. Культурная активность посетителей художественного музея: роль культурного капитала и мотиваций // Культура и искусство, № 5.

УШКАРЕВ 2018б: Ушкарев, А. Культурный капитал как драйвер потребления искусства // Обсерватория культуры, Т. 15. № 2.

УШКАРЕВ 2019: Ушкарев, А. Аудитория искусства в социальных измерениях. Санкт-Петурбург: Алетейя.

ФОХТ-БАБУШКИН 1987: Фохт-Бабушкин, Ю., Художественная культура и развитие личности. Проблемы долгосрочного планирования / Отв. ред. Ю. Фохт-Бабушкин. Москва: Наука.

ФОХТ-БАБУШКИН и др. 1982: Ю. Фохт-Бабушкин, В. Нейгольдберг, В. Дмитриевский и др., Человек в мире художественной культуры. Приобщение к искусству: процесс и управление / Отв. ред. Ю. Фохт-Бабушкин. Москва.

BOURDIEU 1977: Bourdieu, P. Outline of a theory of practice. Cambridge: Cambridge University Press.

BOURDIEU 1994: Bourdieu, P. Distinction: A Social Critique of the Judgement of Taste // Grusky, D. (ed.) Social Stratification: Class, Race, and Gender in Sociological Perspective, Boulder: WestviewPress.

BRIDA et al. 2014: Brida, J.G., Dalle-Nogare, C., Scuderi R., How Often to a Museum? Motivations matter //Bozen Economics \& Management Paper Series, No 16/2014. Retrieved 02.02.2019 from http://pro1.unibz.it/projects/economics/repec/bemps16.pdf.

Gallup Kompas. Retrieved 02.02.2019 from http://www.gallup.dk/.

NotTEN et al. 2013: Notten, N., Lancee, B., van de Werfhorst, H.G. and Ganzeboom, H.B.G., Educational stratification in cultural participation: Cognitive competence or status motivation, GINI Discussion Paper no. 77.

SEAMAN 2006: Seaman, B.A. Empirical Studies of Demand for the Performing Arts // Ginsburgh, A., Throsby, D. (eds.) Handbook on the Economics of Art and Culture. Vol. 1. North-Holland: Elsevier Science.

STIGLER-BECKER 1977: Stigler, G.J. and Becker, G.S, De Gustibus non est disputandum, American Economic Review, 67 (2).

Александр УШКАРЕВ

Государственный институт искусствознания

Москва, Россия

al_ush@mail.ru 